\title{
Mitochondrial division inhibitor-1 induces mitochondrial hyperfusion and sensitizes human cancer cells to TRAIL-induced apoptosis
}

\author{
MAMORU AKITA $^{1,2}$, MIKI SUZUKI-KARASAKI ${ }^{3}$, KYOKO FUJIWARA $^{1}$, CHINATSU NAKAGAWA $^{3}$, \\ MASAYOSHI SOMA ${ }^{1}$, YUKIHIRO YOSHIDA ${ }^{2}$, TOYOKO OCHIAI ${ }^{3}$, \\ YASUAKI TOKUHASHI ${ }^{2}$ and YOSHIHIRO SUZUKI-KARASAKI ${ }^{1,4}$ \\ ${ }^{1}$ Innovative Therapy Research Group, Nihon University Research Institute of Medical Science, \\ ${ }^{2}$ Department of Orthopedic Surgery, Nihon University School of Medicine, Tokyo 173-8610; \\ ${ }^{3}$ Department of Dermatology, Nihon University Surugadai Hospital, Tokyo 101-8309; ${ }^{4}$ Division of Physiology, \\ Department of Biomedical Sciences, Nihon University School of Medicine, Tokyo 173-8610, Japan
}

Received May 1, 2014; Accepted June 18, 2014

DOI: $10.3892 /$ ijo.2014.2608

\begin{abstract}
Tumor necrosis factor-related apoptosis-inducing ligand (TRAIL) is a promising candidate for cancer treatment, but some cancer cell types are resistant to TRAIL cytotoxicity. Therefore, overcoming this resistance is necessary for effective TRAIL therapy. Mitochondrial morphology is important for the maintenance of cell function and survival, and is regulated by the delicate balance between fission and fusion. However, the role of mitochondrial morphology dynamics in TRAIL-induced apoptosis is unknown. Here we show that mitochondrial division inhibitor-1 (mdivi-1), an inhibitor of dynamin-related protein1 (Drp1), modulates mitochondrial morphology and TRAIL-induced apoptosis in human cancer cells. mdivi-1 treatment $(\geq 12.5 \mu \mathrm{M})$ caused dose- and time-dependent cell death in malignant melanoma, lung cancer and osteosarcoma cells, while sparing normal cells. mdivi-1 also sensitized cancer cells to TRAIL-induced apoptosis. This potentiation of apoptosis occurred through a caspase-depependent mechanism including the mitochondrial and endoplasmic reticulum (ER) stress pathways. Mdivi-1 potentiated mitochondrial oxidative stress, a major cause of mitochondrial and ER stresses, as evidenced by increases in mitochondrial reactive oxygen species levels, mitochondrial mass, and cardiolipin oxidation. Live cell fluorescence imaging
\end{abstract}

Correspondence to: Dr Yoshihiro Suzuki-Karasaki, Division of Physiology, Department of Biomedical Sciences, Nihon University School of Medicine, 30-1 Oyaguchikamimachi, Itabashi-ku, Tokyo 173-8610, Japan

E-mail: suzuki.yoshihiro@nihon-u.ac.jp

Key words: tumor-selective killing, tumor necrosis factor-related apoptosis-inducing ligand, mitochondrial division inhibitor-1, mitochondrial fission, ROS using MitoTracker Red CMXRos revealed that Mdivi-1 caused substantial mitochondrial hyperfusion. Moreover, silencing of Drp1 expression also caused mitochondrial hyperfusion and sensitized cancer cells to TRAIL-induced apoptosis. Our results suggest that cancer cells are more vulnerable than normal cells to a perturbation in mitochondrial morphology dynamics and that this higher susceptibility can be exploited to selectively kill cancer cells and sensitize to TRAIL.

\section{Introduction}

Apo2 ligand/tumor necrosis factor (TNF)-related apoptosis-inducing ligand (Apo2L/TRAIL), a member of the TNF superfamily, has emerged as a promising candidate for cancer therapy on the basis of its capacity to induce apoptosis in various types of cancer cells without significant cytotoxicity toward normal cells (1-4). Binding of TRAIL to two death receptors (DRs), TRAIL receptor (TRAIL-R)1/DR4 and TRAIL-R2/DR5 triggers the extrinsic and intrinsic apoptotic pathways $(5,6)$. However, some cancer cell types such as melanoma, non-small cell lung cancer and osteosarcoma are resistant to TRAIL, despite expressing DRs $(7,8)$. Moreover, TRAIL-responsive tumors acquire resistance rendering TRAIL therapy ineffective. Thus, drugs that overcome this resistance are urgently needed for effective TRAIL therapy.

Mitochondria are highly dynamic organelles with a reticular organization that is regulated by the balance between fission and fusion. Mitochondrial morphology is critical for cell function and survival $(9,10)$. The mitochondrial network depends on the delicate balance between two antagonistic machineries responsible for fission and fusion of the mitochondrial membrane. Disruption of mitochondrial fission leads to an extensively interconnected and collapsed mitochondrial network, while defects in mitochondrial fusion lead to mitochondrial fragmentation and loss of mitochondrial DNA (11). Mitochondrial fission helps to eliminate damaged mitochondria through autophagy (mitophagy) (12). On the other hand, 
mitochondrial fusion facilitates the exchange of mitochondrial DNA and metabolites required for mitochondrial function (13). Efficient mitochondrial fusion is important for cell viability, because cells defective in fusion exhibit reduced growth, decreased mitochondrial membrane potential $\left(\Delta \Psi_{\mathrm{m}}\right)$, and defective respiration (14). Mitochondrial fusion and fission in mammalian cells are controlled by dynamin-related proteins with GTPase activity, namely mitofusin 1/2 (Mfn1/2), optic atrophy 1 and dynamin-related protein 1 (Drp1). Mfn1/2, and optic atrophy 1 act in concert to regulate mitochondrial fusion and cristae organization, while Drp1 regulates mitochondrial fission $(14,15)$.

Controversial results have been reported on the role of mitochondrial fission in cancer cell apoptosis. Mitochondrial fission has been shown to act as both pro-apoptotic and anti-apoptotic events in cancer cell apoptosis, depending on the cell types and the apoptotic stimuli applied (16-22). At present, there is no model that can depict the dual functions of mitochondrial fission in cancer cell apoptosis. Mitochondrial division inhibitor-1 (mdivi-1) was recently identified as a potent inhibitor of Drp1 GTPase in yeast and mammalian cells (23). To gain insight into the role of mitochondrial morphology dynamics in cancer cell apoptosis, we examined whether mdivi-1 affected mitochondrial morphology and TRAIL-induced apoptosis. We found that mdivi-1 killed different cancer cell types including malignant melanoma, lung cancer and osteosarcoma cells, while sparing normal cells. mdivi-1 treatment also sensitized cancer cells to TRAIL-induced apoptosis. This potentiation of apoptosis by mdivi-1 occurred through activation of mitochondrial and endoplasmic reticulum (ER) pathways by increasing mitochondrial oxidative stress, a major cause of these pathways.

\section{Materials and methods}

Reagents. Soluble recombinant human TRAIL and mdivi-1 were obtained from Enzo Life Sciences (San Diego, CA, USA). Thapsigargin, rotenone, antimycin A, oligomycin and carbonyl cyanide $\mathrm{p}$-trifluoromethoxyphenylhydrazone (FCCP) were obtained from Sigma-Aldrich (St. Louis, MO, USA). The general caspase inhibitor z-VAD-fluoromethylketone (FMK), caspase-3/7-specific inhibitor z-DEVD-FMK, caspase-8-specific inhibitor $z$-IETD-FMK, and caspase-9-specific inhibitor z-LEHD-FMK were purchased from Merck Japan. The reagents were dissolved in dimethylsulfoxide and diluted with Hanks' balanced salt solution (HBSS) (pH 7.4) to a final concentration of $<0.1 \%$ before use.

Cell culture. The human melanoma cell lines, human A549 lung cancer cells, osteosarcoma cell lines, and human fetal fibroblastlike lung WI-38-40 cells were obtained from Health Science Research Resource Bank (Osaka, Japan). These cell lines were cultured in Dulbecco's modified Eagle's medium (DMEM; Sigma-Aldrich) supplemented with $10 \%$ fetal bovine serum (FBS; Sigma-Aldrich) in a $5 \% \mathrm{CO}_{2}$ incubator. Normal human epidermal melanocytes were obtained from Cascade Biologics and cultured in DermaLife Basal Medium supplemented with DermaLife M LifeFactors (Kurabo, Osaka, Japan). Cells were harvested by incubation in $0.25 \%$ trypsin-ethylenediaminetetraacetic acid (Life Technologies Japan) for $5 \mathrm{~min}$ at $37^{\circ} \mathrm{C}$.
Cell viability and apoptosis measurements. Cell viability was measured with WST-8 assay using the Cell Counting kit (Dojindo, Kumamoto, Japan), a colorimetric assay based on the formation of a water-soluble formazan product. Cells $\left(1 \times 10^{3} /\right.$ well $)$ were seeded in 96 -well plates and cultured with the agents to be tested for $72 \mathrm{~h}$ at $37^{\circ} \mathrm{C}$ in a $5 \% \mathrm{CO}_{2}$ incubator. Then $1 / 10$ volume of WST- 8 reagent was added, incubated for $1 \mathrm{~h}$ at $37^{\circ} \mathrm{C}$ and absorbance at $450 \mathrm{~nm}$ was measured using a microplate reader (ARVO MX, Perkin Elmer, Japan). Apoptotic cell death was quantitatively assessed by doublestaining with fluorescein isothiocyanate (FITC)-conjugated Annexin $\mathrm{V}$ and propidium iodide (PI) as previously described (24). Briefly, cells (2x10\%/well) in 24-well plates were incubated with the agents to be tested for $24 \mathrm{~h}$ in $10 \%$ FBS-containing medium at $37^{\circ} \mathrm{C}$. Subsequently, the cells were stained with FITC-conjugated Annexin V and PI using a commercially available kit (Annexin V FITC Apoptosis Detection kit I; BD Biosciences, Japan). The stained cells were evaluated in the FACSCalibur and analyzed using CellQuest software (BD Biosciences). Four cellular subpopulations evaluated: viable cells (Annexin $\mathrm{V}^{-} / \mathrm{PI}^{-}$); early apoptotic cells (Annexin $\mathrm{V}^{+} / \mathrm{PI}^{-}$); late apoptotic cells (Annexin $\mathrm{V}^{+} / \mathrm{PI}^{+}$); and necrotic/damaged cells (Annexin $\mathrm{V}^{-} / \mathrm{PI}^{+}$). Annexin $\mathrm{V}^{+}$cells were considered to be apoptotic cells.

Mitochondrial morphology imaging. Mitochondrial morphology was analyzed by staining with the mitochondria-targeting dye MitoTracker ${ }^{\circledR}$ Red CMXRos (Life Technologies Japan) followed by observation under a fluorescence microscope. Briefly, cells (1x10\%/well) in DMEM were placed on coverslips (Asahi Glass Co, Tokyo, Japan) and treated with the agents to be tested for $24 \mathrm{~h}$ at $37^{\circ} \mathrm{C}$ in a $5 \% \mathrm{CO}_{2}$ incubator. After removing the medium, the cells were washed and stained with $20 \mathrm{nM}$ MitoTracker Red CMXRos and Hoechst 33342 (Dojindo) in HBSS for $1 \mathrm{~h}$ at $37^{\circ} \mathrm{C}$ in the dark in a $5 \% \mathrm{CO}_{2}$ incubator. The cells were then washed with HBSS and immersed in HBSS to prevent cell damage. Low magnification images were obtained with a fluorescence microscope (IX71 inverted microscope, Olympus, Tokyo, Japan) and analyzed using LuminaVision software (Mitani Corporation, Fukui, Japan). High magnification images were gained and analyzed with EVOS FL Cell Imaging System (Life Technologies Japan).

Caspase-3/7 activation and $\Delta \Psi_{m}$ measurements. Activation of caspase-3/7 and changes in $\Delta \Psi_{\mathrm{m}}$ were simultaneously measured by flow cytometry as previously described (24). Briefly, cells $\left(2 \times 10^{5} / \mathrm{ml}\right)$ in 24 -well plates were treated with the agents to be tested for $24 \mathrm{~h}$ in $10 \% \mathrm{FBS} / \mathrm{DMEM}$ at $37^{\circ} \mathrm{C}$ and then stained with the dual sensor MitoCasp ${ }^{\mathrm{TM}} \mathrm{kit}$ (Cell Technology, Mountain View, CA, USA). Caspase-3/7 activation and $\Delta \Psi_{\mathrm{m}}$ were evaluated using FACSCalibur, and the data were analyzed using CellQuest software.

Caspase-12 activation assay. Activation of caspase-12 in living cells was measured using the caspase-12 inhibitor ATAD-FMK conjugated to FITC (FITC-ATAD-FMK) as previously described (24). FITC-ATAD-FMK is cell-permeable and non-toxic and binds irreversibly to active caspase-12, but not inactive caspase-12, in apoptotic cells. Briefly, cells 
( $\left.2 \times 10^{5} / \mathrm{ml}\right)$ in 24 -well plates were treated with the agents to be tested for $24 \mathrm{~h}$ in $10 \% \mathrm{FBS} / \mathrm{DMEM}$ at $37^{\circ} \mathrm{C}$ and then stained with a CaspGlow ${ }^{\mathrm{TM}}$ Fluorescein Active Caspase-12 Staining kit (BioVision, Mountain View, CA, USA). Fluorescence was determined using the FL-1 channel of FACSCalibur and analyzed using CellQuest software.

Determination of surface DR4/DR5 expression. DR4 and DR5 expression on the cell surface was assessed by flow cytometry as previously described (25). Briefly, cells (5x105/100 $\mu \mathrm{l})$ were incubated with monoclonal anti-human DR4 and DR5 antibodies or mouse isotype-matched control antibodies (R\&D Systems, Minneapolis, MN, USA) for $30 \mathrm{~min}$ at $4^{\circ} \mathrm{C}$. The cells were then centrifuged into a pellet, resuspended in phosphate-buffered saline (PBS), and then incubated with phycoerythrin-conjugated goat $\mathrm{F}\left(\mathrm{ab}^{\prime}\right)_{2}$ anti-mouse IgG (R\&D Systems) for $30 \mathrm{~min}$ at $4^{\circ} \mathrm{C}$. The fluorescence was measured using the FL-2 channel of FACSCalibur and analyzed using CellQuest software.

Mitochondrial oxidative stress measurements. Mitochondrial oxidative stress was measured by monitoring mitochondrial ROS production using MitoSOX ${ }^{\mathrm{TM}}$ Red (Life Technologies Japan) by flow cytometry and the signals were calibrated as previously described (26). Briefly, cells $\left(5 \times 10^{5} / 500 \mu \mathrm{l}\right)$ suspended in HBSS were incubated with the agents to be tested for $4 \mathrm{~h}$ at $37^{\circ} \mathrm{C}$ and then incubated with $5 \mu \mathrm{M}$ MitoSOX for $15 \mathrm{~min}$ at $37^{\circ} \mathrm{C}$ for loading. The cells were washed, resuspended in HBSS on ice, centrifuged at $4^{\circ} \mathrm{C}$ and analyzed for their fluorescence. Mitochondrial oxidative stress was also assessed by measuring oxidation of cardiolipin by flow cytometry using the fluorescent dye 10-N-nonyl acridine orange (NAO, Life Technologies Japan), which binds to nonoxidized cardiolipin, but not oxidized cardiolipin, as previously described (26). Briefly, cells $\left(5 \times 10^{5} / 500 \mu 1\right)$ suspended in HBSS were incubated with the agents to be tested for $4 \mathrm{~h}$ at $37^{\circ} \mathrm{C}$ and then incubated with $100 \mathrm{nM}$ NAO for $15 \mathrm{~min}$ at $37^{\circ} \mathrm{C}$. The cells were washed and resuspended in HBSS on ice, and fluorescence was analyzed. Red fluorescence (MitoSOX) and green fluorescence (NAO) were measured using the FL-2 and FL-1 channel, respectively, of FACSCalibur and analyzed using CellQuest software. The data were expressed as $F / F_{0}$, where $F_{0}$ is the fluorescence of unstimulated cells and $F$ is the fluorescence of stimulated cells.

Drpl gene silencing by siRNA. Mitochondrial fission was inhibited by downregulating Drp1 expression using small interfering RNA. Cells $\left(2.5 \times 10^{5} /\right.$ well $)$ were plated in 6 -well plates and transfected with $20 \mathrm{nM}$ each of Drp1-targeting siRNA or scrambled control siRNA (Santa Cruz Biotechnology, Santa Cruz, CA, USA) using Lipofectamine RNA/Max Kit (Life Technologies Japan) according to the manufacturer's instructions and cultured for $72 \mathrm{~h}$ at $37^{\circ} \mathrm{C}$ in a $5 \% \mathrm{CO}_{2}$ incubator. The downregulation of Drp1 protein levels was assessed by immunoblotting.

Immunoblotting. The levels of Drp1, pro-caspase and cleaved caspase-3 proteins were determined using immunoblotting. For the analysis of Drpl protein levels, cells $\left(1 \times 10^{6} / \mathrm{ml}\right)$ were washed with PBS, and lysed with RIPA buffer containing protease inhibitors. Whole cell lysates ( $30 \mu \mathrm{g}$ protein) were subjected to reducing sodium dodecyl sulfate polyacrylamide gel electrophoresis (SDS-PAGE) using a 10\% separation gel (ATTO Co., Tokyo, Japan) and transferred onto polyvinylidene difluoride membranes (Nippon Millipore, Tokyo, Japan). The membranes were blocked with BlockAce (Dainippon Sumitomo Pharma, Osaka, Japan) for $1 \mathrm{~h}$ at room temperature, washed with PBS containing $0.1 \%$ Tween-20, then incubated with anti-Drp1 antibody (Santa Cruz Biotechnology) overnight at $4{ }^{\circ} \mathrm{C}$ followed by incubation with horseradish peroxidase (HRP)-conjugated species-specific anti-rabbit Ig (GE Healthcare Japan, Tokyo, Japan) for $1 \mathrm{~h}$ at room temperature. After washing, immunoreactive proteins were detected using the ECL Prime Kit (GE Healthcare Japan). For the analysis of caspase-3 protein levels, cells $\left(1 \times 10^{6} / \mathrm{ml}\right)$ in $10 \% \mathrm{FBS} / \mathrm{DMEM}$ were treated with the agents to be tested for the indicated times, washed with PBS and lysed with RIPA buffer. Whole cell lysates (15 $\mu$ g protein) were separated by SDS-PAGE using 4-12\% gradient gel (Life Technologies Japan) and transferred onto Immobilon-P membranes (Nippon Millipore). The membranes were blocked with Blocking-One (Nacalai Tesque, Tokyo, Japan) overnight at $4^{\circ} \mathrm{C}$, and then incubated with anti-caspase- 3 or anti-cleaved caspase-3 antibodies (Cell Signaling Technology Japan) overnight at $4^{\circ} \mathrm{C}$, followed by incubation with HRP-conjugated secondary antibody (GE Healthcare Japan) for $1 \mathrm{~h}$ at room temperature. After washing in PBS containing $0.1 \%$ Tween-20, immunoreactive bands were visualized with Chemi-Lumi One Super (Nacalai Tesque). To verify equal loading, the membranes were re-probed with monoclonal antiGAPDH (Santa Cruz Biotechnology) or anti- $\beta$-actin antibody (Sigma-Aldrich).

Statistical analysis. Data were analyzed by one-way analysis of variance followed by the post-hoc Tukey's test. All values were expressed as mean $\pm \mathrm{SE}$, and $\mathrm{P}<0.05$ was considered to be significant.

\section{Results}

Mdivi-1 reduces cell viability and sensitizes cancer cells to TRAIL cytotoxicity. We examined the ability of mdivi-1 to affect cell viability in human cancer cells. For this purpose, we utilized different cancer cell types with different sensitivities to TRAIL: the human malignant melanoma cell lines A375 and GAK and the human lung cancer cell line A549. Cells were treated with mdivi-1 and TRAIL alone or in combination for 24-72 h, and cell viability was measured using WST-8 assay. In all cell lines tested, mdivi- 1 alone up to $50 \mu \mathrm{M}$ only modestly decreased cell viability in the initial $24 \mathrm{~h}$. However, mdivi-1 $(\geq 12.5 \mu \mathrm{M}$ ) caused a robust decrease in cell viability at $72 \mathrm{~h}$ in a dose-dependent manner (Fig. 1A-C). GAK cells, which were relatively sensitive to TRAIL cytotoxicity, were also sensitive to mdivi-1 (maximum of $40 \%$ decrease at $50 \mu \mathrm{M}$ ). Moreover, mdivi-1 markedly sensitized these cells to TRAIL cytotoxicity during the initial $24 \mathrm{~h}$ (data not shown) and this effect became increasing prominent over another $48 \mathrm{~h}$ (Fig. 1A-C). The human osterosarcoma cell lines MG63, HOS and G292 were relatively resistant to TRAIL, because treatment with $100 \mathrm{ng} / \mathrm{ml}$ TRAIL for $72 \mathrm{~h}$ resulted in only a modest decrease (maximum of $30 \%$ ) in cell viability. In contrast, mdivi-1 alone 

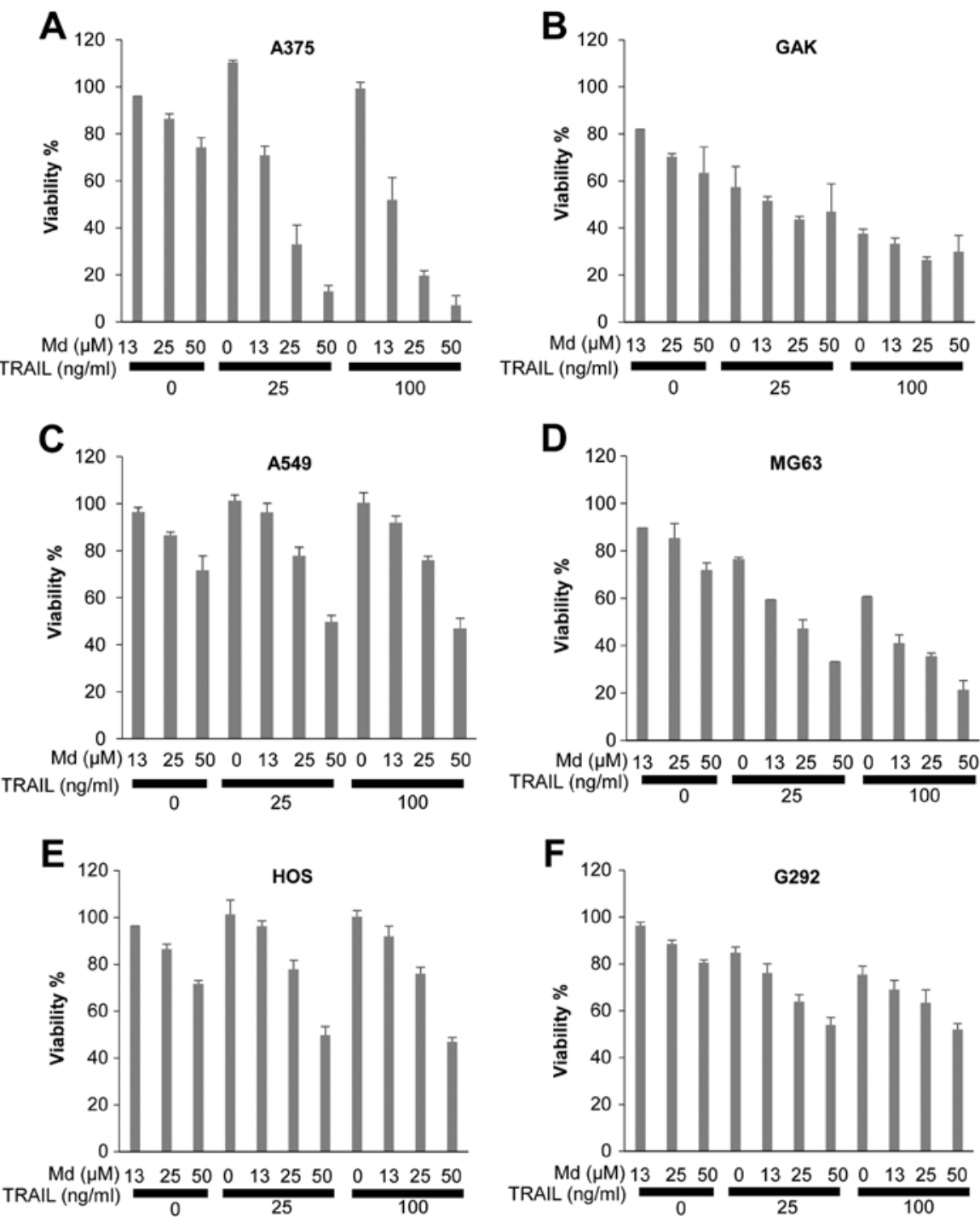

Figure 1. Mdivi-1 reduces cell viability and sensitizes cancer cells to TRAIL cytotoxicity. (A-F): (A) A375, (B) GAK, (C) A549, (D) MG63, (E) HOS and (F) G292 cells were plated in 96 -well plates and treated with 25 or $100 \mathrm{ng} / \mathrm{ml}$ TRAIL in the absence or presence of 25 or $50 \mu \mathrm{M}$ mdivi-1 (Md) for $72 \mathrm{~h}$ and analyzed for viability using WST-8 assay in triplicates. The data show means \pm SE for a representative experiment $(\mathrm{n}=3-5)$.

dose-dependently decreased cell viability in all these cell lines. In addition, mdivi-1 markedly potentiated TRAIL cytotoxicity (Fig. 1D-F). This effect was clearer in TRAIL-sensitive cells (MG63) than in TRAIL-resistant cells (HOS and G292). These results show that mdivi-1 decreases cell viability and sensitizes cancer cells to TRAIL cytotoxicity.

mdivi-1 potentiates DR4/5-mediated apoptosis in cancer cells. To clarify the mode of cell death potentiated by mdivi-1, A375 cells were analyzed for Annexin V and propidium iodide (PI) double staining by flow cytometry. Fig. 2A shows typical results. mdivi-1 up to $25 \mu \mathrm{M}$ alone induced minimal increase in Annexin $\mathrm{V}^{+}$cells but enhanced the increase by TRAIL, indicating that mdivi-1 sensitizes these cells to TRAIL-induced apoptosis. This sensitization was dosedependent with a minimal effective dose of $12.5 \mu \mathrm{M}$ and was clearly observed with TRAIL ( $\geq 25 \mathrm{ng} / \mathrm{ml}$ ) (Fig. 2A and B). In contrast, as previously reported by others (27), thapsigargin up to $1 \mu \mathrm{M}$ was ineffective at inducing apoptosis, and mdivi-1 did not potentiate the effect (Fig. 2A and C). mdivi-1 also sensitized the cells to apoptosis induced by the anti-DR5 or DR4 agonist antibodies (Fig. 2D), suggesting that the sensitization mainly occurs through increased DR4/DR5 apoptotic signaling. Similarly, mdivi-1 substantially sensitized A549 cells to TRAIL-induced apoptosis (Fig. 2E). TRAIL up to $100 \mathrm{ng} / \mathrm{ml}$ minimally increased the number of necrotic (Annexin $\mathrm{V}^{-} / \mathrm{PI}^{+}$) cells $(<2.5 \%)$, and mdivi-1 did not significantly increase this cell population in either of the two cell types, indicating that necrotic cell death plays a minor role in the potentiation effect. In contrast, MG63 cells displayed robust basal necrotic cell death $(11.1 \pm 2.4 \%, n=3)$, which was increased by TRAIL up to $16 \%$, while mdivi-1 decreased it. Interestingly, as basal necrotic cell death increased, apoptosis was induced to a lesser extent in response to TRAIL and/or mdivi-1, suggesting a negative effect of necrotic cell death on apoptosis rate. Collectively, these results show that mdivi-1 potentiates DR4/5-mediated cell death in different human cancer cell types. 
A
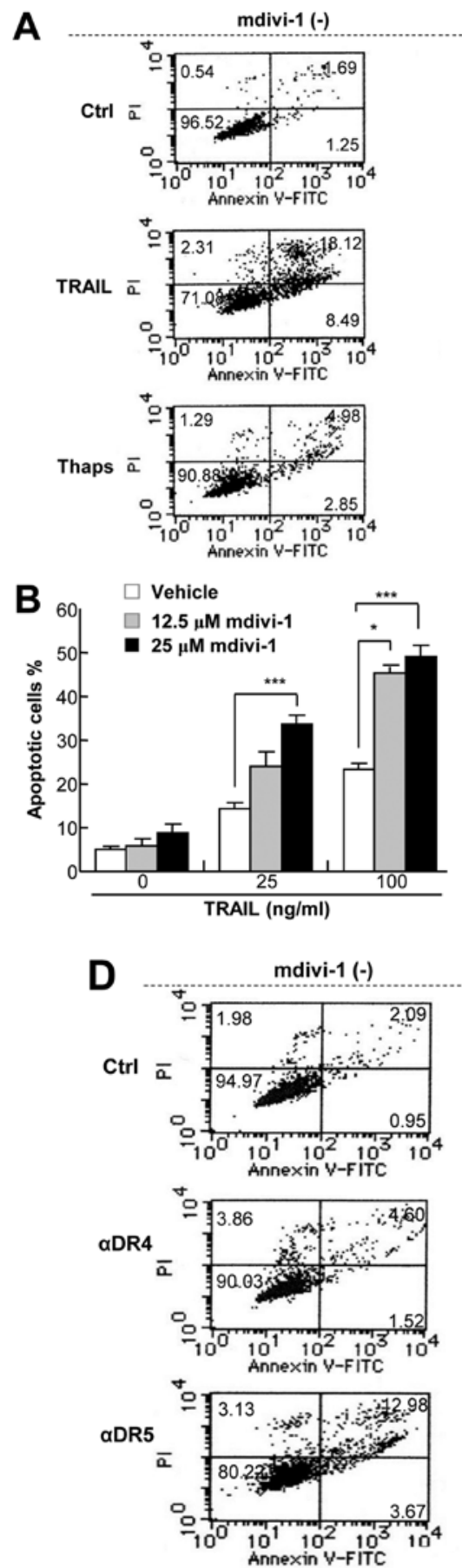
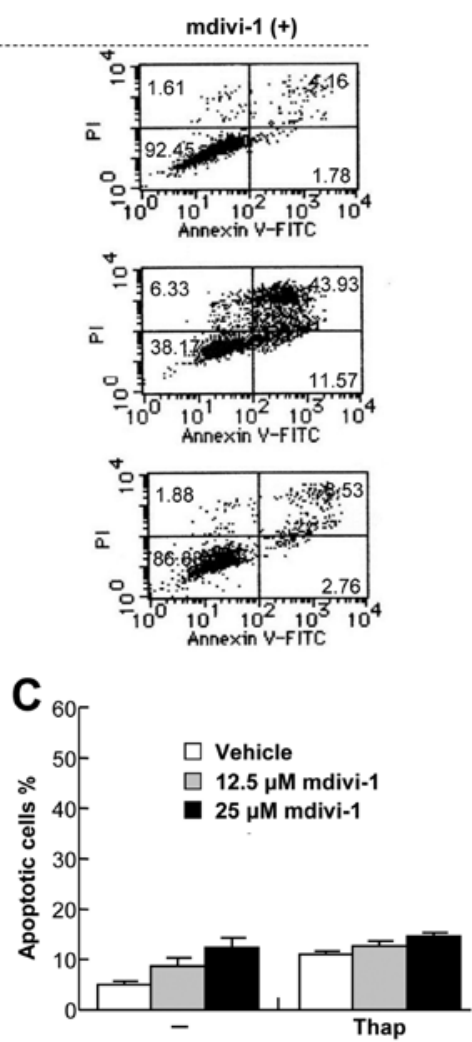

mdivi-1 (+)
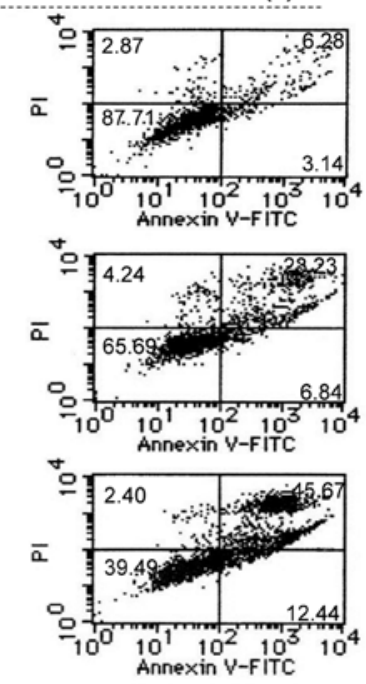

E

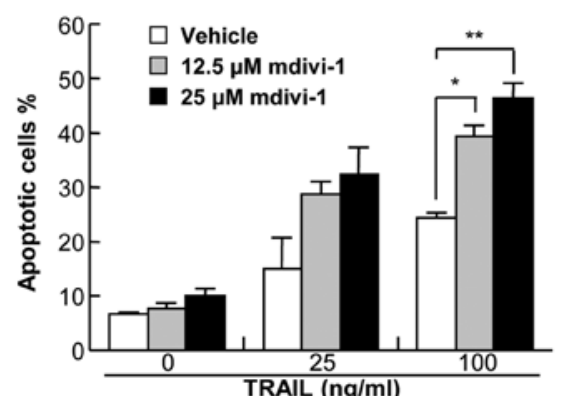

Figure 2. Mdivi-1 potentiates DR4/5-mediated apoptosis in cancer cells. (A) A375 cells were plated in 24 -well plates and treated with 25 ng/ml TRAIL or $1 \mu \mathrm{M}$ thapsigargin (Thap) for $24 \mathrm{~h}$ in the absence or presence of $25 \mu \mathrm{M}$ mdivi-1. The cells were then analyzed for Annexin V/PI staining by flow cytometry. The data are present as a representative histogram. (B-D) The cells were treated with (B) TRAIL at the indicated concentrations, (C) Thap or (D) $1 \mu \mathrm{g} / \mathrm{ml}$ of agonistic anti-DR5 or anti-DR4 antibody in the absence or presence of 12.5 or $25 \mu \mathrm{M}$ mdivi-1 for $24 \mathrm{~h}$, and then analyzed for Annexin V/PI staining by flow cytometry. Annexin $\mathrm{V}^{+}$ cells were considered to be apoptotic cells. (B and C) The data represent means $\pm \mathrm{SE}(\mathrm{n}=3-5)$. (D) Representative histograms are shown. ${ }^{*} \mathrm{P}<0.05$; ${ }^{* * *} \mathrm{P}<0.001$. (E) A549 cells were treated with $25 \mathrm{ng} / \mathrm{ml}$ TRAIL in the absence or presence of $25 \mu \mathrm{M}$ mdivi-1 for $24 \mathrm{~h}$. The cells were then analyzed for Annexin V/PI staining in a flow cytometer. The data represent means $\pm \mathrm{SE}(\mathrm{n}=3) .{ }^{*} \mathrm{P}<0.05 ;{ }^{* *} \mathrm{P}<0.01$. 

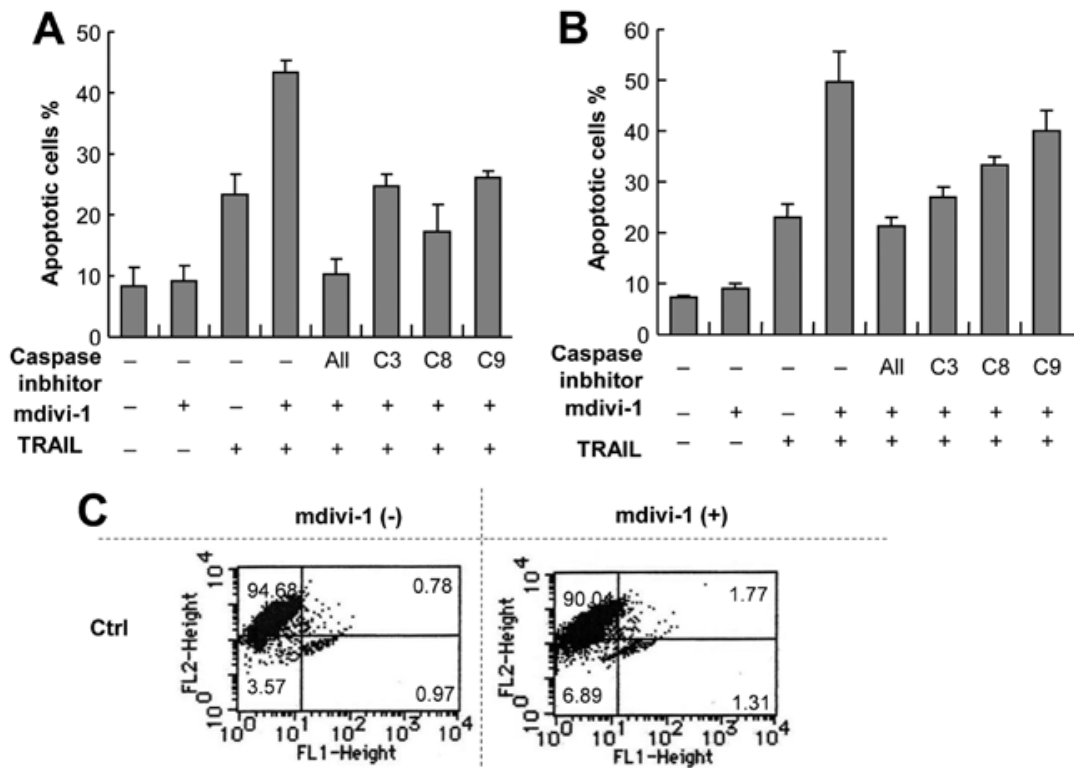

mdivi-1 (+)

TRAIL
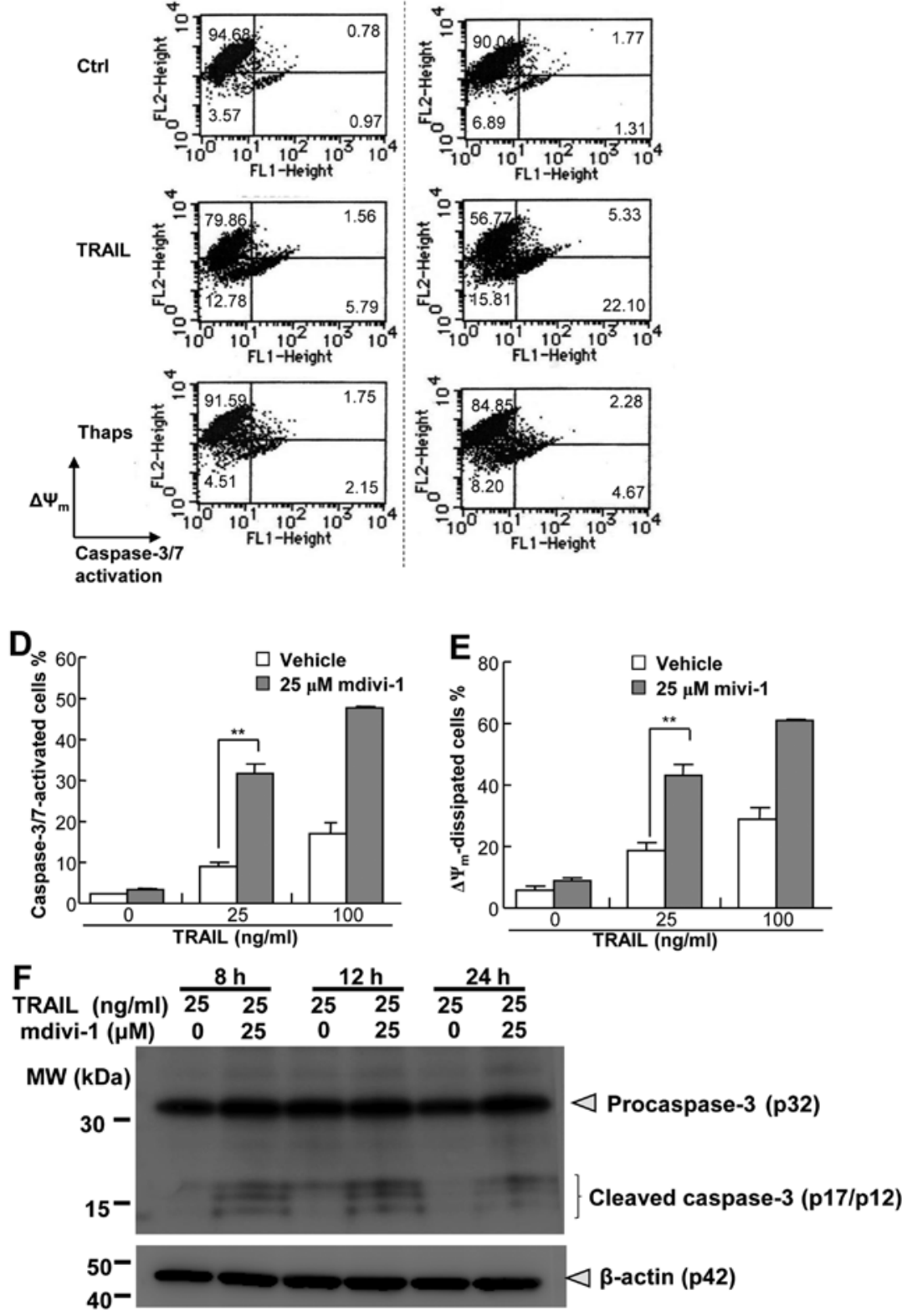

Figure 3. Potentiation of apoptosis by mdivi-1 occurs through a caspase-dependent mechanism. (A) A375 cells and (B) A549 cells were treated with $100 \mathrm{ng} / \mathrm{ml}$ TRAIL alone or in combination with $25 \mu \mathrm{M}$ mdivi-1 in the absence or presence of $10 \mu \mathrm{M}$ of the general caspase inhibitor z-VAD-fmk (All), the caspase-3 inhibitor z-DEVD-fmk (C3), the caspase-8 inhibitor z-IETD-fmk (C8) or the caspase-9 inhibitor z-LEHD-fmk (C9) for $24 \mathrm{~h}$. Apoptotic cells were assessed using Annexin V/ PI staining in a flow cytometer. Annexin $\mathrm{V}^{+}$cells were considered to be apoptotic cells. The data represent means $\pm \mathrm{SE}(\mathrm{n}=3)$. (C-E) A375 cells were treated with $100 \mathrm{ng} / \mathrm{ml}$ TRAIL alone or in combination with $25 \mu \mathrm{M}$ mdivi-1 for $24 \mathrm{~h}$, and analyzed for caspase-3/7 activation (C and D) and $\Delta \Psi_{\mathrm{m}}$ depolarization (C and E) by flow cytometry using a Dual Sensor MitoCasp kit. A representative histogram is shown in (C). The data represent means \pm SE $(n=3)$. ${ }^{* *} \mathrm{P}<0.01$. (F) A375 cells were treated with $25 \mathrm{ng} / \mathrm{ml}$ TRAIL in the absence or presence of $25 \mu \mathrm{M}$ mdivi-1 for the indicated times, washed with PBS and lysed with RIPA buffer. Whole cell lysates were separated by SDS-PAGE and transferred onto membranes. After blocking overnight at $4^{\circ} \mathrm{C}$, the membranes were incubated with anti-caspase-3 or anti-cleaved caspase- 3 antibodies overnight at $4^{\circ} \mathrm{C}$, followed by incubation with HRP-conjugated secondary antibody for $1 \mathrm{~h}$ at room temperature and visualized. To verify equal loading, the membranes were re-probed with an anti- $\beta$-actin antibody. MW (kDa) represents the molecular weights of marker proteins. 
Potentiation of apoptosis by mdivi-1 occurs through a caspase-dependent pathway. Because of their easy handling, high responsivity to mdivi-1, and the availability of normal counterparts, we used A375 and A549 cells as models for investigating the molecular mechanisms underlying the potentiation effect of mdivi-1. To elucidate the possible role of the caspase cascade, we examined the effects of an array of caspase inhibitors on the potentiation mediated by mdivi-1. The general caspase inhibitor z-VAD-FMK completely abolished the potentiation of apoptosis in A375 cells, indicating that the effect is caspase-dependent (Fig. 3A). The caspase-8-specific inhibitor z-IETD-FMK, the caspase-9-specific inhibitor z-LEHD-FMK and the caspase-3/7-specific inhibitor z-DEVD-FMK all abolished the potentiation of apoptosis almost completely, suggesting the involvement of both the extrinsic and intrinsic death pathways in the potentiation (Fig. 3A). Similar results were obtained with A549 cells except that the caspase- 8 and caspase-9 inhibitors were less effective than the caspase-3 inhibitor (Fig. 3B). These results show that the potentiation of apoptosis occurs through a caspase-dependent pathway involving caspase- 3 activation. To provide insight into the mechanisms underlying the potentiation, we examined the effects of TRAIL and mdivi- 1 on $\Delta \Psi_{\mathrm{m}}$ and caspase-3 activation, because loss of $\Delta \Psi_{\mathrm{m}}$ impairs mitochondrial integrity disruption, resulting in the release of pro-apoptotic factors and caspase- 3 activation. Simultaneous measurements using a $\Delta \Psi_{\mathrm{m}}$-specific dye and a caspase-3-specific substrate revealed that TRAIL induced substantial $\Delta \Psi_{\mathrm{m}}$ dissipation and caspase- 3 activation in A375 cells in a dose-dependent manner within $24 \mathrm{~h}$ (Fig. 3C). Although mdivi-1 up to $50 \mu \mathrm{M}$ alone caused only modest loss of $\Delta \Psi_{\mathrm{m}}$ and caspase-3 activation, it markedly potentiated the effects of TRAIL (Fig. 3C-E). In contrast, mdivi-1 had little effects on $\Delta \Psi_{\mathrm{m}}$ or caspase-3 activation induced by thapsigargin (Fig. 3C). Immunoblotting provided additional evidence for the potentiation of TRAIL-induced caspase-3 activation by Mdivi-1. Mdivi-1 or TRAIL alone induced minimal cleavage of procaspase-3 (p32), while the combination of TRAIL and mdivi-1 caused a robust increase in levels of cleaved (active) caspase-3 (p17/p12). The cleaved caspase-3 was first detected at $8 \mathrm{~h}$ after stimulation and levels continued to increase for another $4 \mathrm{~h}$. Thereafter levels decreased probably due to additional processing (Fig. 3F). These results show that the potentiation of apoptosis by mdivi-1 occurs through a caspase-dependent pathway including the intrinsic pathway.

Potentiation of apoptosis by mdivi-1 is mediated by caspase-12 activation. To explore the role of ER death pathway in the potentiation of apoptosis by mdivi-1, we examined the ability of mdivi-1 to modulate activation of caspase-12, an ER-associated caspase, which occurs independently of the extrinsic and intrinsic death pathways. Measurements of caspase-12 activity using a specific substrate revealed that basal caspase-12 activation was low $(1.46 \pm 0.19 \%, \mathrm{n}=3)$, and $100 \mathrm{ng} / \mathrm{ml}$ TRAIL and $50 \mu \mathrm{M}$ mdivi-1 individually induced caspase-12 activation to a similar extent (10.4 and 15.4\%, respectively). However, synergistic effects were observed when these two agents were used together (59.9\%) (Fig. 4A). Next, we examined the effect of z-ATAD-FMK, a caspase-12-specific inhibitor, on
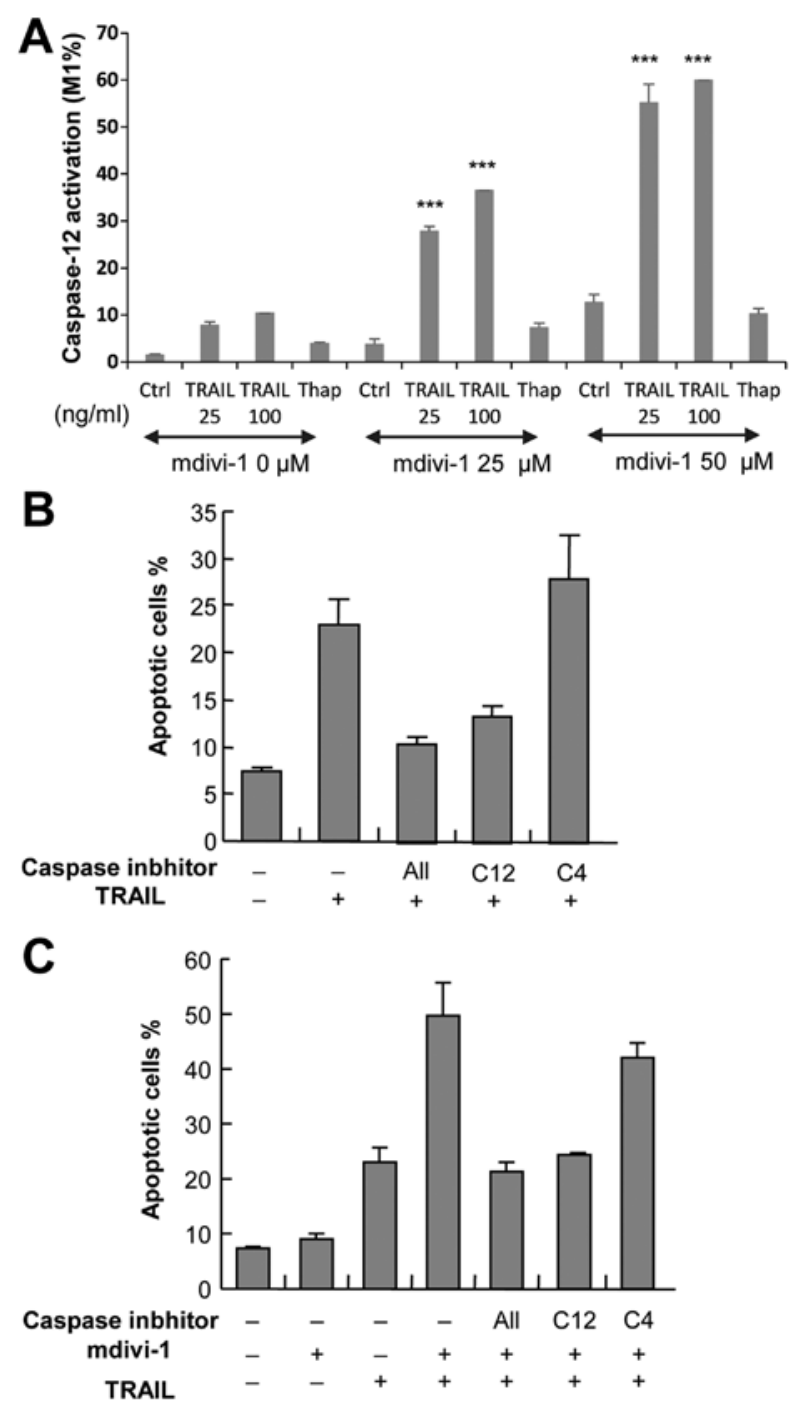

Figure 4. Potentiation of apoptosis by mdivi-1 is mediated by caspase-12 activation. (A) A375 cells were treated with 25 or $100 \mathrm{ng} / \mathrm{ml}$ TRAIL alone in the absence or presence of 25 or $50 \mu \mathrm{M}$ mdivi-1 for $24 \mathrm{~h}$, and analyzed for their caspase-12 activation using FITC-ATAD-FMK by flow cytometry. The data are shown as percentages of cells with caspase-12 activation (M1) in the histogram and represent means $\pm \mathrm{SE}(\mathrm{n}=3)$. ${ }^{* * *} \mathrm{P}<0.001$. (B and $\left.C\right)$ The cells were treated with (B) $25 \mathrm{ng} / \mathrm{ml}$ TRAIL alone or (C) in combination with $50 \mu \mathrm{M}$ mdivi-1 in the absence or presence of $10 \mu \mathrm{M}$ of the general caspase inhibitor z-VAD-fmk (All), the caspase-12 inhibitor z-ATAD-FMK (C12) or the caspase-4 inhibitor z-LEVD-FMK (C4) for $24 \mathrm{~h}$. Apoptotic cells were assessed by Annexin V/PI staining in a flow cytometer. Annexin $\mathrm{V}^{+}$cells were considered to be apoptotic cells. The data represent means $\pm \mathrm{SE}(\mathrm{n}=3)$.

apoptosis. TRAIL-induced apoptosis was strongly (maximum of $60 \%$ ) inhibited by z-ATAD-FMK, while z-LEVD-FMK, an inhibitor of another ER-associated enzyme, caspase-4, was ineffective (Fig. 4B). Moreover, the potentiation of TRAILinduced apoptosis by mdivi-1 was completely abolished by treatment with z-ATAD-FMK, while z-LEVD-FMK exhibited only modest $(<10 \%)$ inhibition (Fig. 4C). Taken together, these results suggest that potentiation of apoptosis by mdivi-1 is mediated by caspase- 12 activation.

Potentiation of apoptosis by mdivi-1 is preceded by depolarization and increased mitochondrial oxidative stress and mass. Persistent cell membrane depolarization is an early and 

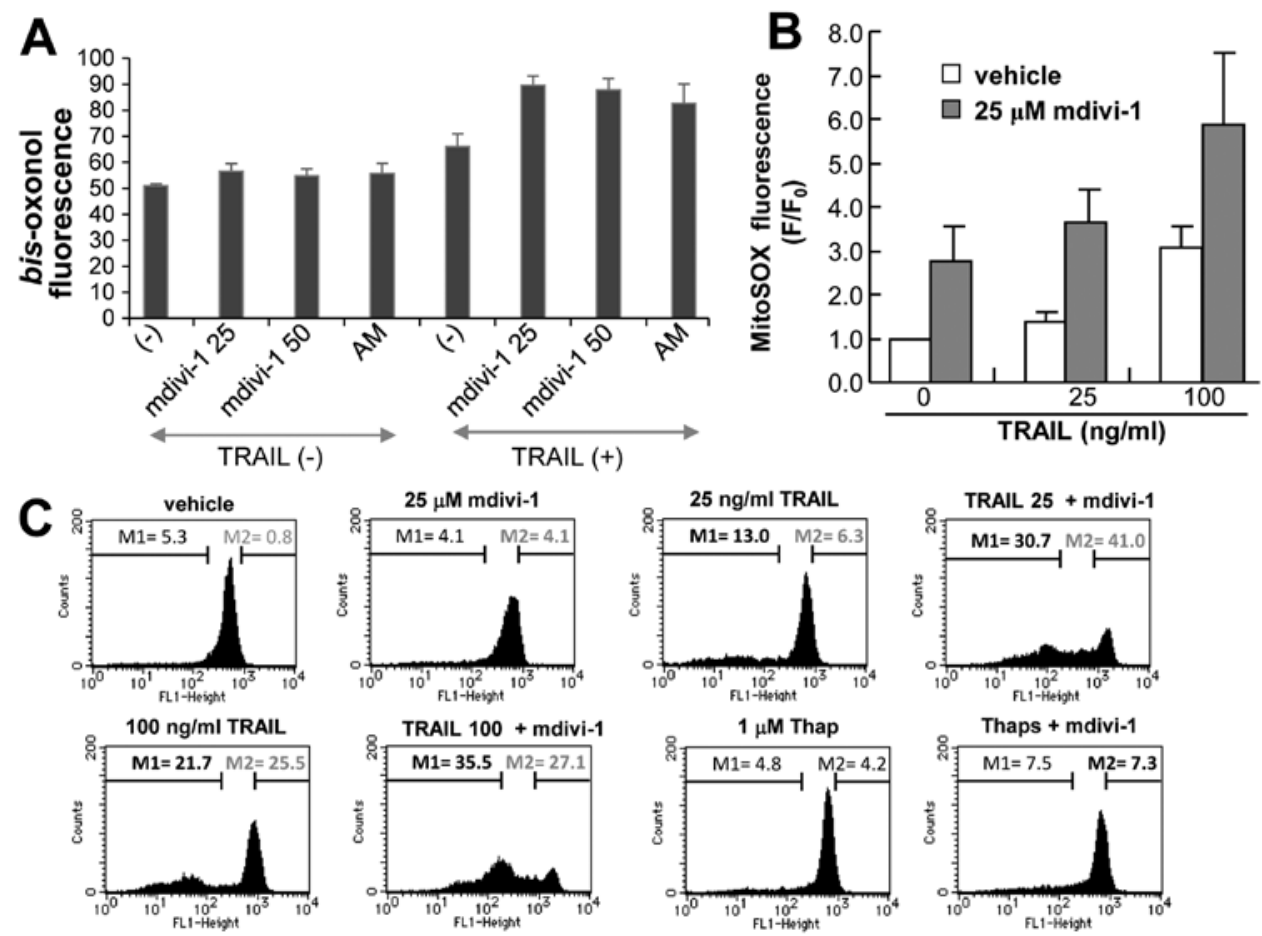

Figure 5. Potentiation of apoptosis by mdivi-1 is preceded by depolarization and increased mitochondrial oxidative stress and mass. (A) A375 cells were treated with 25 or $50 \mu \mathrm{M}$ mdivi-1 with or without of $100 \mathrm{ng} / \mathrm{ml}$ TRAIL for $4 \mathrm{~h}$, and analyzed for cell membrane depolarization using bis-oxonol by flow cytometry. The data are shown as mean fluorescence intensity and represent means $\pm \mathrm{SE}(\mathrm{n}=3)$. (B) The cells were treated with $25 \mathrm{or} 100 \mathrm{ng} / \mathrm{ml}$ TRAIL in the absence or presence of 25 or $50 \mu \mathrm{M}$ mdivi-1 for $4 \mathrm{~h}$, then incubated with (B) $5 \mu \mathrm{M}$ MitoSOX or (C) $100 \mathrm{nM}$ NAO for $15 \mathrm{~min}$ at $37^{\circ} \mathrm{C}$ for loading, and analyzed for red and green fluorescence using the FL-2 and FL-1 channel, respectively, of a flow cytometer and analyzed using CellQuest software. In (B), the data are expressed as $F / F_{0}$, where $F_{0}$ is the fluorescence in unstimulated cells and $F$ is the fluorescence in stimulated cells. The data represent mean $\pm \operatorname{SE}(\mathrm{n}=3)$. In $(C)$, a representative histogram with the percentages of M1 and M2 cells are shown.

prerequisite event in apoptosis and caspase- 3 activation in human malignant tumor cells induced by diverse pro-apoptotic stimuli including TRAIL $(24,28-31)$. To elucidate the possible role of depolarization in the TRAIL-sensitizing effect of mdivi-1, we examined the ability of mdivi-1 to induce depolarization using the anionic dye bis-oxonol in a flow cytometer. Mdivi-1 alone up to $50 \mu \mathrm{M}$ caused only modest depolarization. However, mdivi-1 ( $\geq 25 \mu \mathrm{M}$ ) potentiated TRAIL-induced depolarization as effectively as $5 \mu \mathrm{g} / \mathrm{ml}$ antimycin A (Fig. 5A). Since increase in mitochondrial ROS (mROS) levels is a major cause of mitochondrial integrity disruption and the intrinsic pathway, we measured the effect of mdivi-1 on mROS levels using MitoSOX, a fluoroprobe that targets mitochondria and serves as a selective probe for superoxide in these organelles $(32,33)$. As shown in Fig. 5B, 25 and $100 \mathrm{ng} / \mathrm{ml}$ TRAIL increased MitoSOX fluorescence by 1.5 - and 3-fold, respectively, at $4 \mathrm{~h}$. Mdivi-1 alone also robustly increased MitoSOX fluorescence (3-fold). When TRAIL and mdivi-1 were used together, their effects were additive (Fig. 5B). We also assessed oxidation of cardiolipin, a phospholipid that is associated with cytochrome $c$ in the outer surface of the inner mitochondrial membrane. Because the fluorescent dye NAO binds to non-oxidized cardiolipin, but not to oxidized cardiolipin, measurement of NAO fluorescence can be used to monitor oxidation of cardiolipin in mitochondria (34). Fig. 5C shows a representative histogram. TRAIL increased oxidation of cardiolipin in a dose-dependent manner, as shown by the decrease in NAO fluorescence (an increase in the M1 population). Although mdivi-1 alone did not affect the oxidation of cardiolipin, it markedly potentiated the effect of TRAIL (Fig. 5C). In contrast, thapsigargin alone had a minimal effect on the oxidation of cardiolipin, and mdivi-1 only slightly altered the effect of the compound. A considerable increase in NAO fluorescence (an increase in the M2 population) was also observed in cells treated with TRAIL alone or TRAIL+mdivi-1, suggesting an increase in mitochondrial mass. However, unlike the MitoSOX signals and cardiolipin oxidation, the mitochondrial mass changes were not TRAIL dose-dependent. In contrast, thapsigargin had a minimal effect on mitochondrial mass. Collectively, these results show that the potentiation of TRAIL-induced apoptosis by mdivi-1 is preceded by depolarization and increased mitochondrial oxidative stress and mass, all of which are potentiated by the compound.

Effects of mdivi-1 are tumor-selective. To examine the effect of mdivi-1 on cell survival, primary melanocytes were treated with TRAIL and/or mdivi-1, and analyzed for Annexin V and PI double staining by flow cytometry. As shown in Fig. 6A, TRAIL and mdivi-1 alone or in combination induced minimal apoptosis in the cells despite robust cell surface expression of DR4 and DR5 (25). We also examined the effect of TRAIL and/or mdivi-1 on the survival of WI-38 fibroblast-like lung cells. Again, TRAIL and mdivi-1 alone or in combination induced minimal apoptosis in these cells (Fig. 6B) despite substantial cell surface expression of DR5 (Fig. 6C). Collectively, these findings show that the effects of mdivi-1 are tumor-selective. 

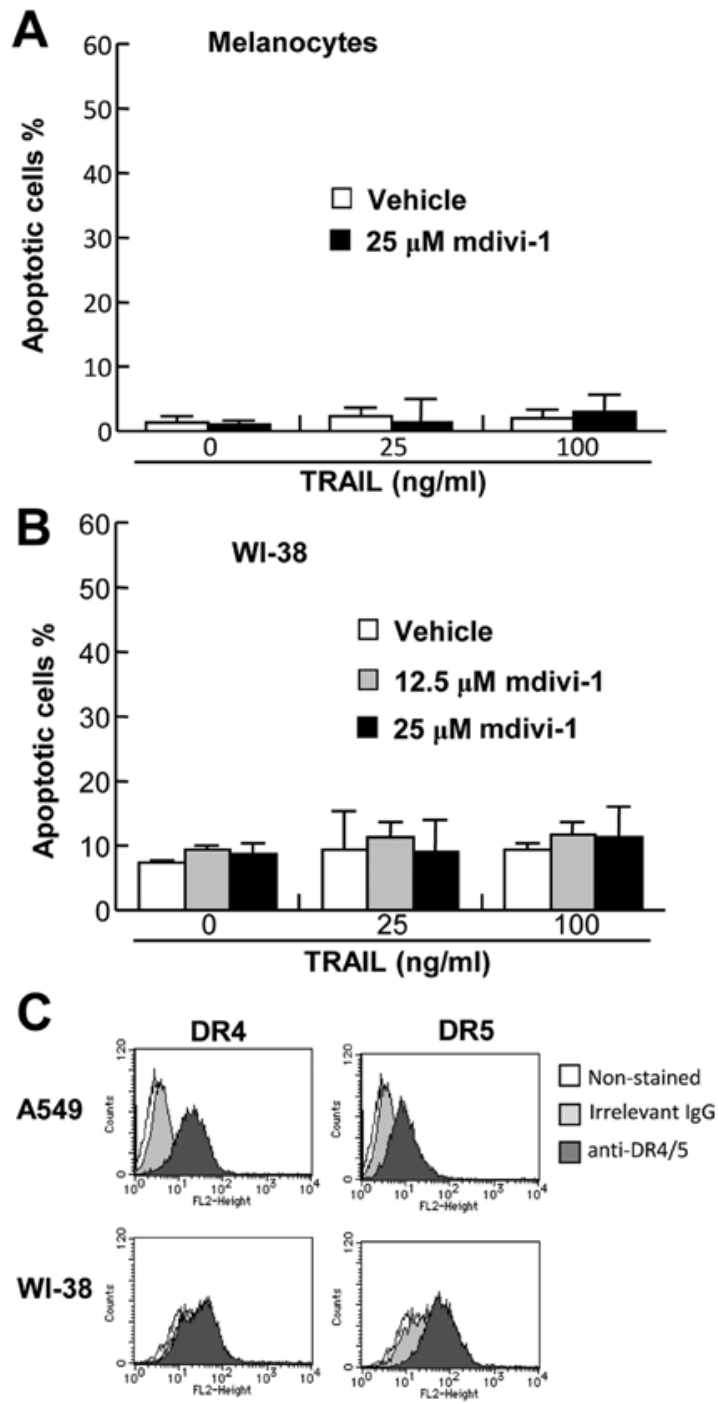

Figure 6. Mdivi-1 cytotoxicity is tumor-selective. (A) Melanocytes and (B) WI-38 fibroblasts were treated with 25 or $100 \mathrm{ng} / \mathrm{ml}$ TRAIL with or without 12.5 or $25 \mu \mathrm{M}$ Mdivi-1 for $24 \mathrm{~h}$. Apoptotic cells were measured by Annexin V/PI staining in a flow cytometer. Annexin $\mathrm{V}^{+}$cells were considered to be apoptotic cells. The data represent means \pm SE $(n=3)$. (C) WI-38 fibroblasts were incubated with a monoclonal antibody against human DR4 or DR5 or an isotype-matched control antibody for $30 \mathrm{~min}$ at $4^{\circ} \mathrm{C}$. The cells were pelleted by centrifugation, resuspended in PBS, and incubated with phycoerythrin-conjugated goat $\mathrm{F}\left(\mathrm{ab}^{\prime}\right) 2$ anti-mouse $\mathrm{IgG}$ for $30 \mathrm{~min}$ at $4^{\circ} \mathrm{C}$. Fluorescence was measured using the FL-2 channel of a flow cytometer and analyzed using CellQuest software. A representative histogram is shown $(n=3)$.

Mdivi-1 exerts its TRAIL-sensitizing effects through the modulation of mitochondrial morphology. To evaluate the role of mitochondrial morphology dynamics in the TRAIL-sensitizing effect of mdivi-1, we examined its effect on mitochondrial morphology. Cells were loaded with the mitochondria-targeting dye MitoTracker Red and examined under a fluorescence microscope. A reticular network radiating from the nucleus was clearly observed in untreated A375 cells (Fig. 7A). As expected, marked mitochondrial morphological changes were observed at $24 \mathrm{~h}$ after the addition of mdivi-1. Robust mitochondrial hyperfusion with a bias towards one of the poles of the nucleus was observed (Fig. 7A). Mdivi-1 caused similar mitochondrial hyperfusion in A549 and MG63 cells (Fig. 7B and C). To examine whether these effects of mdivi-1 are mediated by an ability to modulate mitochondrial fission, we analyzed the impact of Drp1 gene silencing on the mitochondrial morphology, because Drp1 GTPase activity is essential for mitochondrial fission $(14,15)$. Treatment with Drp1 siRNA for $72 \mathrm{~h}$ resulted in a marked decrease in Drp1 protein expression compared with control cells treated with a control siRNA (Fig. 7D, left panel). In the Drp1 knockdown cells, prominent mitochondrial hyperfusion was observed, as in mdivi-1-treated cells (Fig. 7E). Moreover, Drp1 knockdown by itself did not increase basal apoptosis, while A375 and A549 Drp1 knockdown cells were more susceptible than control cells to TRAIL-induced apoptosis, and this sensitization became more apparent as TRAIL concentrations increased (Fig. 7F and G). The effects of Drp1 knockdown were specific for TRAIL, because it had minimal effects on cellular sensitivity to thapsigargin in either cell type (Fig. 7F and G). These results show that mdivi-1 sensitizes cancer cells to TRAIL by modulating mitochondrial morphology.

\section{Discussion}

In this study we demonstrate for the first time that mdivi-1 kills and sensitizes different human cancer cell types to TRAIL-induced apoptosis. Several lines of evidence indicate that these effects are mediated by mitochondrial morphology modulation: i) After mdivi-1 treatment, marked mitochondrial morphological changes, including mitochondrial hyperfusion with a bias towards a pole of the nucleus, were detected; ii) similar mitochondrial hyperfusion was observed in Drp1 knockdown cells; and iii) Drp1 knockdown also sensitized different cancer cell types to TRAIL-induced apoptosis. Collectively, the present findings indicate that inhibition of mitochondrial fission potentiates apoptosis, suggesting that mitochondrial fission inhibits cancer cell apoptosis. Our findings are similar to previous studies showing that etoposide and arsenic trioxide induce mitochondrial aggregation, an event upstream of cytochrome $c$ release during apoptosis in glioblastoma cells $(35,36)$ and suggest a universal role for mitochondrial network changes during cancer cell apoptosis.

Healthy mitochondria are required for cell health, and numerous diseases including cancer are associated with aberrant mitochondrial network dynamics (37). Consequently, drugs that modulate mitochondrial fission and fusion may restore proper dynamics and have therapeutic potential (37). However, the role of mitochondrial fission in cancer cell apoptosis remains elusive, because controversial results have been reported with regard to its role. Various apoptosis inducers cause extensive fragmentation of mitochondria in cancer cells concomitant with mitochondrial outer membrane permeabilization and cytochrome $c$ release $(19,21)$. Moreover, inhibition of mitochondrial fission by downregulation of Drp1 or Fis1, a counterpart of Drp1, has been shown to delay cytochrome $c$ release, suggesting that mitochondrial fission is important for apoptosis $(16,17,20)$. In contrast, other studies have revealed that Drp1-dependent mitochondrial fragmentation is not a prerequisite for apoptosis and that they are separate events, because mitochondrial fission was neither essential for cytochrome $c$ release nor obligatory 

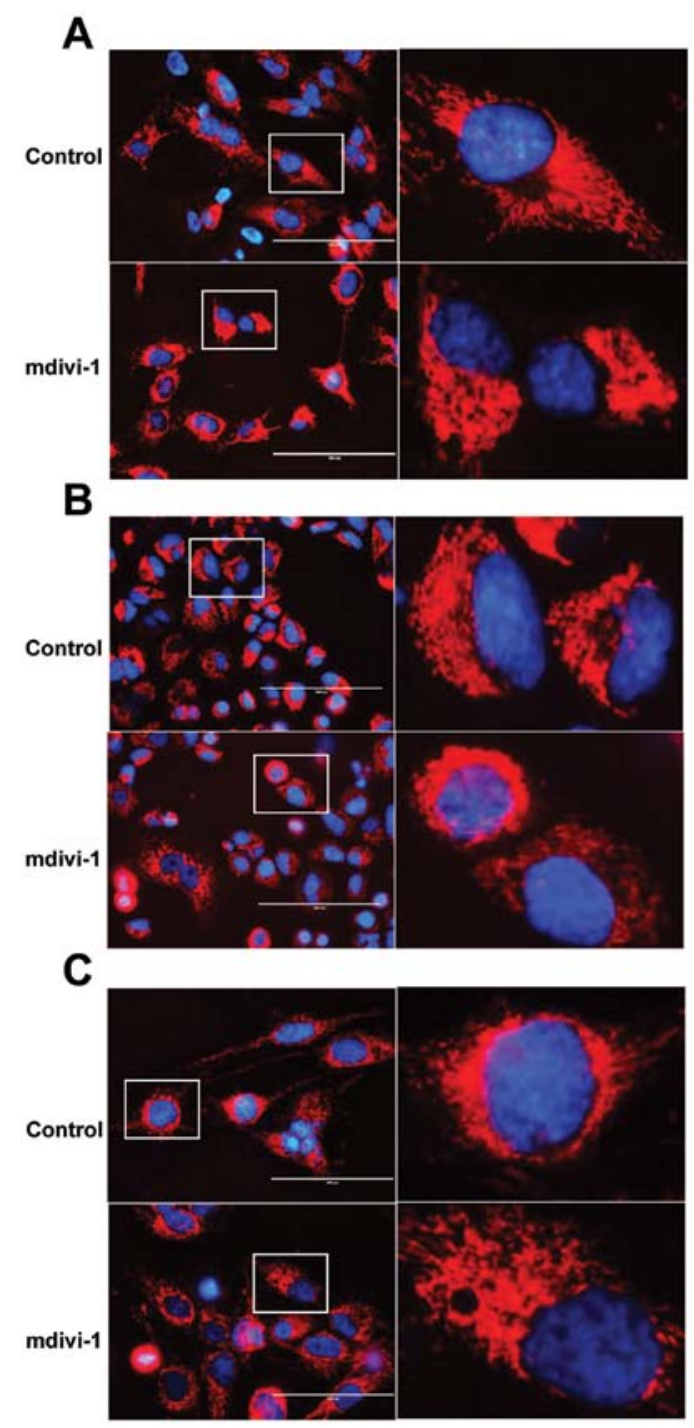
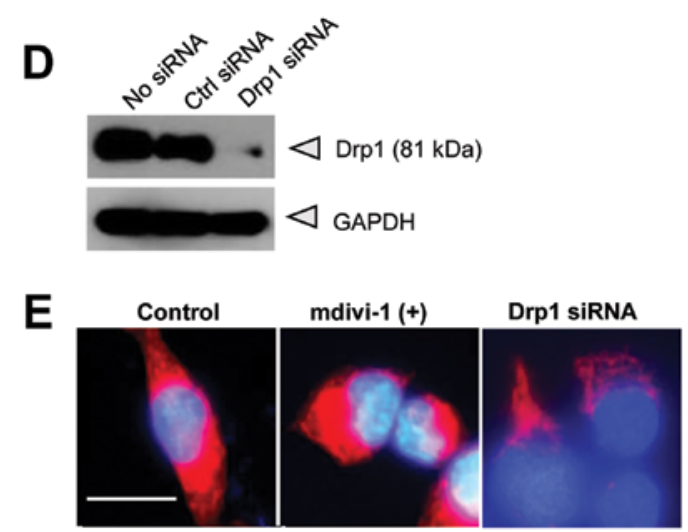

$\mathbf{F}$

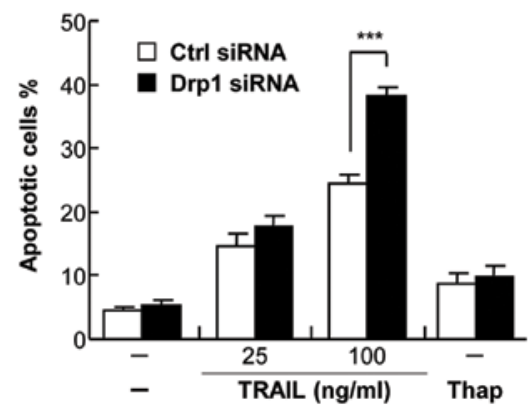

$\mathbf{G}$

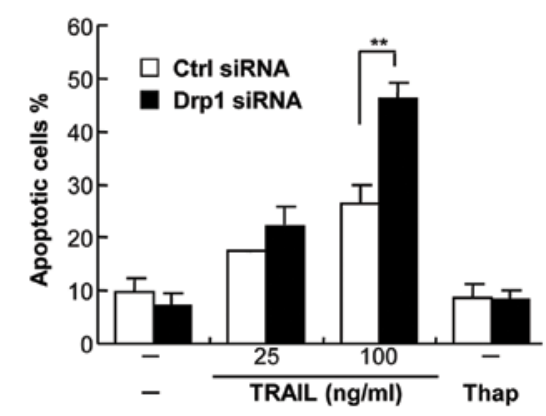

Figure 7. Mdivi-1 triggers TRAIL sensitization by modulating mitochondrial morphology. (A) A375, (B) A549 and (C) MG63 cells plated in coverslips were stained with MitoTracker Red/Hoechst 33342 at $37^{\circ} \mathrm{C}$ for $1 \mathrm{~h}$ and washed. Then the cells were treated with $50 \mu \mathrm{M}$ mdivi-1 for 30 min, and mitochondria within the cells were observed under a fluorescence microscope at x1,200 magnification. Scale bar, $100 \mu \mathrm{m}$. Mitochondria were stained red with MitoTracker Red and nuclei were stained blue with Hoechst 33342. (D) A375 cells in 6-well plates were transfected with $20 \mathrm{nM}$ of Drp1 siRNA or scrambled irrelevant control siRNA (Ctrl siRNA) using the Lipofectamine RNAi/Max kit and cultured for $72 \mathrm{~h}$ at $37^{\circ} \mathrm{C}$ in a $5 \% \mathrm{CO}_{2}$ incubator. The cells were then analyzed for Drp1 protein levels by immunoblotting using an anti-Drp1 antibody. To verify equal loading, the membranes were re-probed with an anti-GAPDH antibody. (E) The cells transfected with Ctrl siRNA or Drp1 siRNA were treated with or without $50 \mu \mathrm{M}$ mdivi-1 for $24 \mathrm{~h}$. After staining with MitoTracker Red/Hoechst 33342, mitochondria within the cells were observed under a fluorescence microscope at x400 magnification. Scale bar, $100 \mu \mathrm{m}$. (F) A375 and (G) A549 cells were plated in 24-well plates, treated with 25 or $100 \mathrm{ng} / \mathrm{ml}$ TRAIL or $1 \mu \mathrm{M}$ thapsigargin (Thaps) for $24 \mathrm{~h}$, and analyzed for apoptosis by Annexin V/PI staining in a flow cytometer. Annexin $\mathrm{V}^{+}$ cells were considered to be apoptotic cells. The data represent means $\pm \mathrm{SE}(\mathrm{n}=3) .{ }^{* *} \mathrm{P}<0.01 ;{ }^{* * *} \mathrm{P}<0.001$.

for apoptosis $(19,22)$. In addition, several lines of evidence suggest that mitochondrial fission is protective against $\mathrm{Ca}^{2+}$ induced apoptosis (14). Human lung cancer cell lines exhibit an imbalance of Drp1/Mfn-2 expression compared with normal human lung epithelial and vascular cells and a state of mitochondrial fragmentation. Lung tumor tissue samples from patients exhibit similar increase in mitochondrial fragmentation compared with normal lung tissue. Consistent with a protective role of mitochondrial fission, inhibition of mitochondrial fragmentation by Drp1 knockdown or mdivi-1 or promotion of mitochondrial fusion by Mfn2 overexpression increases spontaneous apoptosis in lung cancer cells and regress tumor growth in vivo (38). Our data expand these observations and suggest that mitochondrial fission protects different human cancer cell types including melanoma, lung cancer and osteosarcoma cells from apoptosis. Importantly, mdivi-1 had minimal cytotoxicity and TRAIL-sensitizing effect in normal melanocytes and fibroblasts. This indicates that mdivi-1 may be selectively cytotoxic toward tumor cells. Although the mechanisms underlying this selectivity remain to be elucidated, it is plausible that disruption of mitochondrial morphology dynamics preferentially causes mitochondrial dysfunction in cancer cells.

We found that mdivi-1 potentiates multiple pro-apoptotic events, including membrane depolarization, loss of $\Delta \Psi_{\mathrm{m}}$, caspase- 3 and caspase- 12 activation, mROS generation and cardiolipin oxidation. These observations are in accordance with our previous studies showing that diverse compounds 
commonly potentiate these events and TRAIL-induced apoptosis in human malignant tumor cells. These compounds include high $\mathrm{K}^{+}$, ATP-sensitive $\mathrm{K}^{+}$channel inhibitors such as glibenclamide and U37883A $(24,28)$, diallyltrisulfide, a major garlic organosulfur compound (25), the cell-permeable oxidant, $\mathrm{H}_{2} \mathrm{O}_{2}(39)$ and mitochondrial inhibitors such as antimycin A and FCCP (26). A loss of $\Delta \Psi_{m}$ is the main cause of mitochondrial outer membrane permeabilization, mitochondrial integrity disruption and pro-apoptotic protein release. Mitochondrial outer membrane permeabilization allows release of several pro-apoptotic proteins including cytochrome $c$ and apoptosis-inducing factor-1, thereby promoting the activation of the caspase-9-caspase- 3 cascade and processing of key regulatory and structural proteins. Although the precise mechanisms of mitochondrial outer membrane permeabilization are poorly understood, it is widely accepted that an increase in permeabilization of the inner mitochondrial membrane is involved and that mitochondrial permeability transition pores (mPTPs) are thought to play pivotal roles in this process $(40,41)$. mPTPs are putative high-conductance non-specific channels in the inner mitochondrial membrane, which are composed of proteins that link the inner and outer mitochondrial membrane. Several mitochondrial proteins localized in these membranes such as voltage-dependent anion channels and adenine nucleotide translocase are thought to constitute the mPTP. It is thought that concurrent opening of multiple mPTPs causes excess mitochondrial swelling, the physical disorganization of the outer mitochondrial membrane, mitochondrial pro-apoptotic protein release and apoptosis (42). In this regard, it is noteworthy that the potentiation of apoptosis by mdivi-1 was associated with increased mitochondrial mass, a hallmark of mitochondrial swelling. Because adenine nucleotide translocase has three cysteine residues whose oxidation is critical for mPTP opening/ closing, mPTPs are particularly vulnerable to ROS $(40,41,43)$. Consequently, mitochondrial permeability transition can be triggered by excess mROS generation and/or disruption of the mitochondrial redox homeostasis (44-47). In addition, mROS can control cytochrome $c$ release through the oxidation of the mitochondrial phospholipid cardiolipin (46). The enhancement of membrane depolarization may be also important in the potentiation of apoptosis, because persistent depolarization is an early and prerequisite event in TRAIL-induced apoptosis in cancer cells $(24,28)$. Importantly, depolarization and mROS mutually control one another. Depolarization potentiates TRAIL-induced mROS generation, while scavenging of mROS by antioxidants reduces depolarization, and mROS generation by mitochondrial metabolic dysfunction potentiates the depolarization (28). In addition, scavenging of mROS inhibits pro-apoptotic events in the intrinsic and ER death pathways, including $\Delta \Psi_{\mathrm{m}}$ dissipation, caspase-3 and caspase-12 activation, suggesting that mROS plays a central role in the intrinsic and ER death pathways (48). Collectively, our data suggest that mitochondrial oxidative stress play a key role in the TRAIL-sensitizing effect of mdivi-1.

In conclusion, the present study shows that cancer cells are more vulnerable than normal cells to disruption of mitochondrial network dynamics and that this higher susceptibility can be exploited in cancer treatment, in particular in combination therapy with TRAIL.

\section{Acknowledgements}

The authors thank Dr M. Murai and Dr T. Inoue for technical assistance. This study was supported in part by a Grant-in-Aid from the Ministry of Education, Culture, Sports, Science and Technology (KAKENHI 23591631; to Y.S.-K.) and Grants-in-Aid from Nihon University (to Y.S.-K.).

\section{References}

1. Almasan A and Ashkenazi A: Apo2L/TRAIL: apoptosis signaling, biology, and potential for cancer therapy. Cytokine Growth Factor Rev 14: 337-348, 2003.

2. Johnstone RW, Frew AJ and Smyth MJ: The TRAIL apoptotic pathway in cancer onset, progression and therapy. Nat Rev Cancer 8: 782-798, 2008.

3. Wang S: The promise of cancer therapeutics targeting the TNF-related apoptosis-inducing ligand and TRAIL receptor pathway. Oncogene 27: 6207-6215, 2008.

4. Gonzalvez F and Ashkenazi A: New insights into apoptosis signaling by Apo2L/TRAIL. Oncogene 29: 4752-4765, 2010.

5. LeBlanc HN and Ashkenazi A: Apo2L/TRAIL and its death and decoy. Cell Death Differ 10: 66-75, 2003.

6. Kischkel FC, Lawrence DA, Chuntharapai A, Schow P, Kim KJ and Ashkenazi A: Apo2L/TRAIL-dependent recruitment of endogenous FADD and caspase- 8 to death receptors 4 and 5 . Immunity 12: 612-620, 2000.

7. Dyer MJ, MacFarlane M and Cohen GM: Barriers to effective TRAIL-targeted therapy of malignancy. J Clin Oncol 25: 4505-4506, 2007.

8. Dimberg LY, Anderson CK, Camidge R, Behbakht K, Thorburn A and Ford HL: On the TRAIL to successful cancer therapy? Predicting and counteracting resistance against TRAIL-based therapeutics. Oncogene 32: 1341-1350, 2013.

9. Landes T and Martinou JC: Mitochondrial outer membrane permeabilization during apoptosis: the role of mitochondrial fission. Biochim Biophys Acta 1813: 540-545, 2011.

10. Elgass K, Pakay J, Ryan MT and Palmer CS: Recent advances into the understanding of mitochondrial fission. Biochim Biophys Acta 1833: 150-161, 2013.

11. Hoppins S, Lackner $\mathrm{L}$ and Nunnari J: The machines that divide and fuse mitochondria. Annu Rev Biochem 76: 751-780, 2007.

12. Twig G and Shirihai OS: The interplay between mitochondrial dynamics and mitophagy. Antioxid Redox Signal 14: 1939-1951, 2011.

13. Rouzier C, Bannwarth S, Chaussenot A, et al: The MFN2 gene is responsible for mitochondrial DNA instability and optic atrophy 'plus' phenotype. Brain 135: 23-34, 2012.

14. Chen H, Chomyn A and Chan DC: Disruption of fusion results in mitochondrial heterogeneity and dysfunction. J Biol Chem 280: 26185-26192, 2005 .

15. Chang CR and Blackstone C: Dynamic regulation of mitochondrial fission through modification of the dynamin-related protein Drp1. Ann NY Acad Sci 1201: 34-39, 2010.

16. Frank S, Gaume B, Bergmann-Leitner ES, et al: The role of dynamin-related protein 1 , a mediator of mitochondrial fission, in apoptosis. Dev Cell 1: 515-525, 2001.

17. Lee YJ, Jeong SY, Karbowski M, Smith CL and Youle RJ: Roles of the mammalian mitochondrial fission and fusion mediators Fis1, Drp1, and Opa1 in apoptosis. Mol Biol Cell 15: 5001-5011, 2004.

18. Arnoult D, Grodet A, Lee YJ, Estaquier J and Blackstone C: Release of OPA1 during apoptosis participates in the rapid and complete release of cytochrome $\mathrm{c}$ and subsequent mitochondrial fragmentation. J Biol Chem 280: 35742-35750, 2005.

19. Alirol E, James D, Huber D, Marchetto A, Vergani L and Martinou JC: The mitochondrial fission protein hFis1 requires the endoplasmic reticulum gateway to induce apoptosis. Mol Biol Cell 17: 4593-4605, 2006.

20. Estaquier $\mathbf{J}$ and Arnoult D: Inhibiting Drp1-mediated mitochondrial fission selectively prevents the release of cytochrome c during apoptosis. Cell Death Differ 14: 1086-1094, 2007.

21. Suen DF, Norris KL and Youle RJ: Mitochondrial dynamics and apoptosis. Genes Dev 22: 1577-1590, 2008. 
22. Sheridan C, Delivani P, Cullen SP and Martin SJ: Bax- or Bak-induced mitochondrial fission can be uncoupled from cytochrome c release. Mol Cell 31: 570-585, 2008.

23. Cassidy-Stone A, Chipuk JE, Ingerman E, et al: Chemical inhibition of the mitochondrial division dynamin reveals its role in Bax/Bak-dependent mitochondrial outer membrane permeabilization. Dev Cell 14: 193-204, 2008.

24. Suzuki Y, Inoue T, Murai M, Suzuki-Karasaki M, Ochiai T and Ra C: Depolarization potentiates TRAIL-induced apoptosis in human melanoma cells: Role for ATP-sensitive $\mathrm{K}^{+}$channels and endoplasmic reticulum stress. Int J Oncol 41: 465-475, 2012.

25. Murai M, Inoue T, Suzuki-Karasaki M, Ochiai T, Ra C, Nishida S, et al: Diallyl trisulfide sensitizes human melanoma cells to TRAIL-induced cell death by promoting endoplasmic reticulum-mediated apoptosis. Int J Oncol 41: 2029-2037, 2012.

26. Inoue $\mathrm{T}$ and Suzuki-Karasaki Y: Mitochondrial superoxide mediates mitochondrial and endoplasmic reticulum dysfunctions in TRAIL-induced apoptosis in Jurkat cells. Free Radic Biol Med 61: 273-284, 2013.

27. Jiang CC, Chen LH, Gillespie S, et al: Tunicamycin sensitizes human melanoma cells to tumor necrosis factor-related apoptosis-inducing ligand-induced apoptosis by up-regulation of TRAIL-R2 via the unfolded protein response. Cancer Res 67: 5880-5888, 2007.

28. Bortner CD, Gomez-Angelats M and Cidlowski JA: Plasma membrane depolarization without repolarization is an early molecular event in anti-Fas-induced apoptosis. J Biol Chem 276: 4304-4314, 2001.

29. Nolte F, Friedrich O, Rojewski M, Fink RH, Schrezenmeier H and Körper S: Depolarisation of the plasma membrane in the arsenic trioxide $\left(\mathrm{As}_{2} \mathrm{O}_{3}\right)$-and anti-CD95-induced apoptosis in myeloid cells. FEBS Lett 578: 85-89, 2004.

30. Yin W, Li X, Feng S, et al: Plasma membrane depolarization and $\mathrm{Na}, \mathrm{K}$-ATPase impairment induced by mitochondrial toxins augment leukemia cell apoptosis via a novel mitochondrial amplification mechanism. Biochem Pharmacol 78: 191-202, 2009.

31. Suzuki-Karasaki M, Ochiai T and Suzuki-Karasaki Y: Crosstalk between mitochondrial ROS and depolarization in the potentiation of TRAIL-induced apoptosis in human tumor cells. Int J Oncol 44: 616-628, 2014.

32. Robinson KM, Janes MS, Pehar M, et al: Selective fluorescent imaging of superoxide in vivo using ethidium-based probes. Proc Natl Acad Sci USA 103: 15038-15043, 2006.

33. Mukhopadhyay P, Rajesh M, Kashiwaya Y, Haskó G and Pacher P: Simple quantitative detection of mitochondrial superoxide production in live cells. Biochem Biophys Res Commun 358: 203-208, 2007

34. Petit JM, Maftah A, Ratinaud MH and Julien R: 10-N-nonyl acridine orange interacts with cardiolipin and allows the quantification of this phospholipid in isolated mitochondria. Eur J Biochem 209: 267-273, 1992.
35. Haga N, Fujita N and Tsuruo T: Mitochondrial aggregation precedes cytochrome c release from mitochondria during apoptosis. Oncogene 22: 5579-5585, 2003.

36. Haga N, Fujita N and Tsuruo T: Involvement of mitochondrial aggregation in arsenic trioxide $\left(\mathrm{As}_{2} \mathrm{O}_{3}\right)$-induced apoptosis in human glioblastoma cells. Cancer Sci 96: 825-833, 2005.

37. Lackner LL and Nunnari J: Small molecule inhibitors of mitochondrial division: tools that translate basic biological research into medicine. Chem Biol 17: 578-583, 2010.

38. Rehman J, Zhang HJ, Toth PT, et al: Inhibition of mitochondrial fission prevents cell cycle progression in lung cancer. FASEB J 26: 2175-2186, 2012.

39. Tochigi M, Inoue T, Suzuki-Karasaki M, Ochiai T, Ra C and Suzuki-Karasaki Y: Hydrogen peroxide induces cell death in human TRAIL-resistant melanoma through intracellular superoxide generation. Int J Oncol 42: 863-872, 2013.

40. Halestrap AP and Brennerb C: The adenine nucleotide translocase: A central component of the mitochondrial permeability transition pore and key player in cell death. Curr Med Chem 10: $1507-1525,2003$.

41. Lemasters JJ, Theruvath TP, Zhong Z and Nieminen AL: Mitochondrial calcium and the permeability transition in cell death. Biochim Biophys Acta 1787: 1395-1401, 2009.

42. Hail N Jr: Mitochondria: A novel target for the chemoprevention of cancer. Apoptosis 10: 687-705, 2005.

43. Zhivotovsky B, Galluzzi L, Kepp O and Kroemer G: Adenine nucleotide translocase: a component of the phylogenetically conserved cell death machinery. Cell Death Differ 16: $1419-1425,2009$

44. Skulachev VP: Why are mitochondria involved in apoptosis? Permeability transition pores and apoptosis as selective mechanisms to eliminate superoxide-producing mitochondria and cell. FEBS Lett 397: 7-10, 1996.

45. Orrenius S: Reactive oxygen species in mitochondria-mediated cell death. Drug Metab Rev 39: 443-455, 2007.

46. Ott M, Gogvadze V, Orrenius S and Zhivotovsky B: Mitochondria, oxidative stress and cell death. Apoptosis 12: 913-922, 2007

47. Ralph SJ, Rodríguez-Enríquez S, Neuzil J and Moreno-Sánchez R: Bioenergetic pathways in tumor mitochondria as targets for cancer therapy and the importance of the ROS-induced apoptotic trigger. Mol Aspects Med 31: 29-59, 2010.

48. Suzuki-Karasaki Y, Suzuki-Karasaki M, Uchida M and Ochiai T: Depolarization controls TRAIL sensitization and tumor-selective killing of cancer cells: crosstalk with ROS. Front Oncol (In press). 